References

1. Büntgen, U. et al. Nat. Geosci. 9, 231-236 (2016).

2. Sigl, M. et al. Nature 523, 543-549 (2015).

3. Larsen, L. B. et al. Geophys. Res. Lett. 35, L04708 (2008).

4. McDermott, F., Mattey, D. P. \& Hawkesworth, C. Science 294, 1328-1331 (2001).

5. Lamb, H. H. Climate, History and the Modern World (Routledge, 1995).

6. Wanner, H. et al. Quat. Sci. Rev. 30, 3109-3123 (2011).
7. Helama, S., Jones P. D. \& Briffa K. R. Holocene http://dx.doi.org/10.1177/0959683617693898 (2017).

Samuli Helama ${ }^{1 *}$, Phil D. Jones ${ }^{2,3}$ and Keith R. Briffa ${ }^{2}$

'Natural Resources Institute Finland, 96300 Rovaniemi, Finland. ${ }^{2}$ Climatic
Research Unit, University of East Anglia, Norwich NR4 7TJ, UK. ${ }^{3}$ Center of Excellence for Climate Change Research, Department of Meteorology, King Abdulaziz University, Jeddah 21589, Saudi Arabia.

^e-mail: samuli.helama@luke.fi

\title{
Reply to 'Limited Late Antique cooling'
}

Büntgen et al. reply - We agree with Helama et al. in their call for further research into the climate of the first half of the Common Era. However, we argue that they underestimate the combined efficacy of environmental, archaeological and historical indicators in establishing a prolonged period of cold summers across much of the Northern Hemisphere landmass between 536 and about $660 \mathrm{AD}$, which we term the Late Antique Little Ice Age (LALIA) ${ }^{1}$.

Although corresponding to the period of highest volcanic ${ }^{2}$ and lowest solar ${ }^{3}$ activity during the first half of the Common Era, Eurasia's LALIA ${ }^{1,4-6}$ was probably not uniform in space and time, because of the dominant role of internal climate variability. Externally forced climate model simulations for the past two millennia are needed to provide insight into the physical mechanisms of positive feedback loops between ocean, sea-ice and atmosphere, which possibly prolonged the volcanically forced, sharp onset of the LALIA that disrupted civilizations across the Northern Hemisphere. Summer cooling during the later part of the LALIA was possibly amplified by another - as yet unattributed - eruption in $626^{2}$.

Glacier fluctuations offer widespread indications for the LALIA ${ }^{7}$, though have not been considered by Helama et al. There are also a number of limitations in the records Helama et al. cite in opposition to the extent of the LALIA: the Solongotyn Davaa and Yakushima Island tree-ring chronologies contain one sample at the time of interest; the Great Basin composite explains less than 20\% of instrumental temperature variance; the Finnish Lapland data lost long-term amplitude changes during standardization; and the GISP2 ice core record that has an absolute dating bias exceeding a decade during the seventh century. Where such limitations prevail, the true nature of past climate fluctuations cannot be adequately resolved.

Moreover, we challenge the definition and usage of the term Dark Ages Cold
Period $^{8}$. Today most archaeologists, historians and natural scientists are reluctant to use the expression 'Dark Age', which became popular in the nineteenth century to describe pejoratively an imagined episode of savagery and ignorance in western-central Europe, characterized by sparse archaeological remains and scant written sources. Instead, historians currently designate the interval from about $300-700$ as the Late Antiquity, not only for the Roman/ Byzantine and Persian/Islamic empires, but also for other regions. It is imperative that scientists adjust their terminology to reflect the current scholarship in other disciplines.

We further consider that the concept of a Dark Ages Cold Period is limited by its unknown trigger, precise onset, and duration. Although increased climate variability characterized the fourth and fifth centuries ${ }^{1,4-6,8}$, abrupt changes and associated forcing agents have not yet been described. Thus, the emergence of new climatological data and historical concepts allows us to refine the climatologically vague Dark Ages Cold Period as

\section{the LALIA.}

With these points in mind, we conclude by concurring with Helama et al. on the pitfalls of deterministic and reductionist approaches to placing archaeological findings and historical events in the context of environmental fluctuations, including climate change ${ }^{9}$.

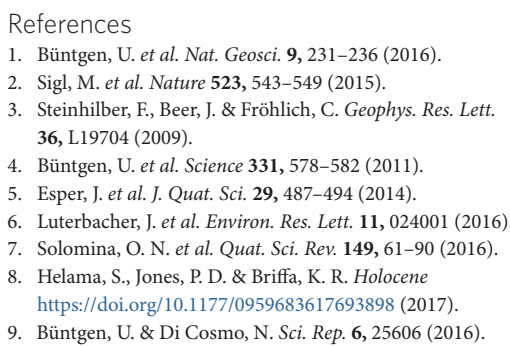

Ulf Büntgen ${ }^{1,2,3 \star}$, Vladimir S. Myglan ${ }^{4}$, Fredrik Charpentier Ljungqvist ${ }^{5,6}$, Michael McCormick7, Nicola Di Cosmo8,
Michael Sig $\left.\right|^{9}$, Johann Jungclaus ${ }^{10}$, Sebastian Wagner ${ }^{11}$, Paul J. Krusic ${ }^{1,12}$, Jan Esper ${ }^{13}$, Jed O. Kaplan ${ }^{14}$, Michiel A.C. de Vaan ${ }^{15}$, Jürg Luterbacher ${ }^{16}$, Lukas Wacker ${ }^{17}$, Willy Tegel ${ }^{18}$, Olga N. Solomina ${ }^{19}$, Kurt Nicolussi ${ }^{20}$, Clive Oppenheimer ${ }^{1}$, Frederick Reinig ${ }^{2}$ and Alexander V. Kirdyanov ${ }^{4,21}$

'Department of Geography, University of Cambridge, Cambridge CB2 3EN, UK. ${ }^{2}$ Swiss Federal Research Institute WSL, CH-8903 Birmensdorf, Switzerland. ${ }^{3} \mathrm{Global}$ Change Research Institute CAS and Masaryk University Brno, 61300 Brno, Czech Republic. ${ }^{4}$ Siberian Federal University, 660041 Krasnoyarsk, Russia. ${ }^{5}$ Department of History, Stockholm University, SE-106 91 Stockholm, Sweden. ${ }^{6}$ Bolin Centre for Climate Research, Stockholm University, SE-106 91 Stockholm, Sweden. ${ }^{7}$ Initiative for the Science of the Human Past (SoHP), Harvard University, Cambridge, Massachusetts 02138, USA. 8 Institute for Advanced Study, School of Historical Studies, Princeton 08540, USA. 'Laboratory of Environmental Chemistry, Paul Scherrer Institute, CH-5232 Villigen, Switzerland. ${ }^{10}$ Max Planck Institute for Meteorology, 20146 Hamburg, Germany. "Institute for Coastal Research,

Helmholtz-Zentrum Geesthacht, D-21502

Geesthacht, Germany. ${ }^{12 N a v a r i n o}$

Environmental Observatory, GR-240001

Messinia, Greece. ${ }^{13}$ Department of Geography, Johannes Gutenberg University, Mainz 55099, Germany. ${ }^{14}$ University of Lausanne, Institute of $\square$ Earth Surface Dynamics, CH-1015 Lausanne, Switzerland. ${ }^{15}$ Department of Linguistics and Information Sciences, University of Lausanne, CH-1015 Lausanne, Switzerland. ${ }^{16}$ Department of Geography, Justus Liebig University, D-35390 Giessen, Germany. ${ }^{17}$ Laboratory for Ion Beam Physics, ETHZ, $\mathrm{CH}-8093$ Zurich, Switzerland. ${ }^{18} \mathrm{Chair}$ of Forest Growth, Albert-Ludwigs University, D-79104 Freiburg, Germany. ${ }^{19}$ Institute of Geography, Russian Academy of Science, Moscow 119017, Russia. ${ }^{20}$ Institute of Geography, University of Innsbruck, 6020 Innsbruck, Austria. ${ }^{21}$ VN Sukachev Institute of Forest SB RAS, Krasnoyarsk RU-660036, Russia. *e-mail: ulf.buentgen@geog.cam.ac.uk 